\title{
A Wideband Frequency Reconfigurable Rectangular Dielectric Resonator Antenna
}

\author{
S. Danesh ${ }^{1}$, M. R. Kamarudin ${ }^{1}$, T. A. Rahman ${ }^{1}$, M. Abedian ${ }^{1}$ and M. Khalily ${ }^{2}$ \\ ${ }^{1}$ Wireless Communication Centre (WCC), Universiti Teknologi Malaysia, UTM Johor, Johor 81310, Malaysia. \\ Email: ramlee@fke.utm.my \\ ${ }^{2}$ Institute for Communication Systems (ICS), home of the 5G Innovation Centre, Department of Electronic \\ Engineering, University of Surrey, Guildford GU2 7XH, U.K
}

\begin{abstract}
A wideband frequency reconfigurable dielectric resonator antenna (DRA) is presented and discussed. The proposed antenna is capable of frequency switching at two different bands between $4.12 \mathrm{GHz}$ and $8.85 \mathrm{GHz}$. The rectangular dielectric resonator with a permittivity of 15 is fed by $U$-shaped microstrip feed line. By setting the switch on the connecting lines of a network that feeds the dielectric element and changing the state of switch from $\mathrm{ON}$ to $\mathrm{OFF}$, a shift of the well-matched operating frequency range is obtained. The total antenna dimensions are $40 \times 45 \times 4.5748 \mathrm{~mm}^{3}$. The results indicate that the proposed antenna with acceptable performance provides two wideband modes with the impedance bandwidth of $49 \%$ and $25 \%$.
\end{abstract}

Index Terms - Dielectric resonator antenna (DRA), Reconfigurable antenna, wideband mode.

\section{INTRODUCTION}

Dielectric resonator antennas (DRAs) are introduced as a possible replacement for conventional metallic antennas in various wireless communication system [1]. They have several advantages such as loss-free conductivity, higher radiation efficiency, small size, wider bandwidth and ease of integration with other passive or active microwave elements. DRAs experience very low loss, therefore they ensure higher efficiency without conductor loss. Additionally, unlike dipole or microstrip antennas that suffer from narrow bandwidths, DRAs have fairly wide bandwidths [2-3].

Besides, the increasing demand of the wireless communication system has entailed antennas to have enhance their performance while being limited to reducing footprint. These design limitations have enforced antenna researchers to study multifunction antennas. As a noteworthy topic to investigate and design multifunction antennas, reconfigurable antennas have received lots of attention, since their capability of changing system requirements or can adopt with environmental conditions. Reconfigurable antennas create numerous multiple, narrow or wide bands to cover several applicable frequency bands, simultaneously. Superior advantage such as reconfigurable capability, multipurpose

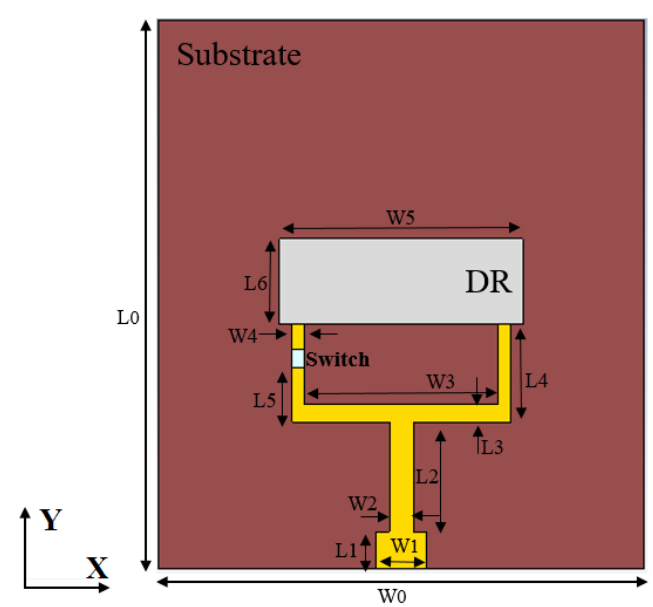

(a)

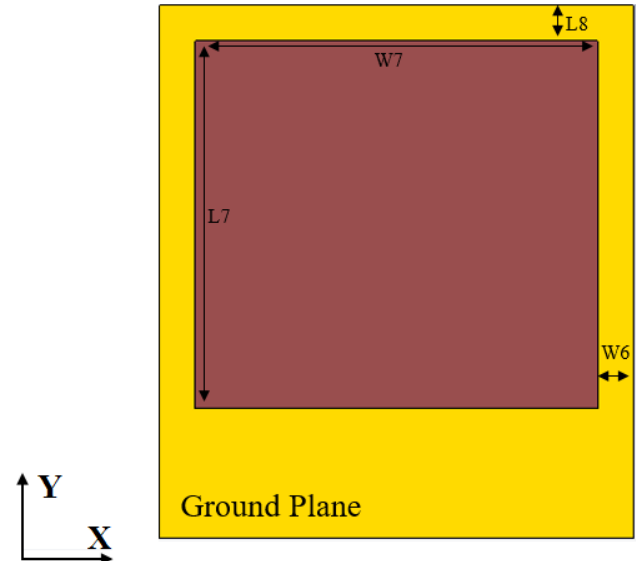

(b)

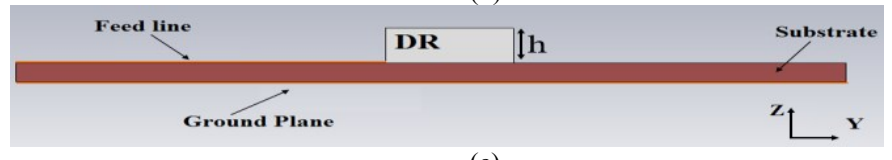

(c)

Fig. 1. Schematic diagram of the proposed reconfigurable dielectric resonator antenna. a) front view, b) back view, c) side view. 
functions, size miniaturization and low cost have given tunable antennas benefit to be integrated into a wireless systems [4-7].Despite many reconfiguration methods existing to conventional metallic antennas, there are rather few frequency reconfiguration mechanisms for the DRA. Some designs of frequency reconfigurable DRAs using different techniques have been reported in the current literature [8-14]. In [8] and [9], the lengths and positions of the parasitic strip and slot can be used to attain tunable frequency of the DRAs, respectively.

In another frequency tunable DR antenna, the air-filled channels are introduced between the ground plane and DRA, and resonant frequency can be shifted to the lower frequencies by sliding metallized dielectric slugs under the dielectric resonator [10]. By locating the switches on the way of feed line in [11] and [12], some narrow bands and dual bands tuning frequency are obtained, respectively. A frequency-tuning DRA is attained by varying the height of water-filled plastic tubes as a resonator [13]. However, the antenna are designed to work at low frequencies (less than $1 \mathrm{GHz}$ ) because of the dielectric losses increment at higher frequencies [14]. Besides, it suffers from large size, so makes it difficult to use in mobile devices. It is noted that, based on literature review, there is no frequency tuning DR antenna that change the frequency from one wideband to another wideband.

In this design, frequency reconfigurable DRA is studied and presented. A switch on the one part of a U-shaped feed line is used to achieve two wideband operation modes. The CST software is used to investigate and analyze the performance of the antenna such as reflection coefficient, gain, efficiency, and radiation pattern. The proposed antenna can be used for several wireless applications between $4.12 \mathrm{GHz}$ and $8.85 \mathrm{GHz}$.

\section{ANTENNA CONFIGURATION AND DESIGN}

Fig. 1 shows the configuration of the proposed antenna, which is consist of a rectangular DR excited by the U-shaped microstrip feed line, and a Taconic substrate with dimensions of $40 \times 45 \times 1.5748 \mathrm{~mm}^{3}$. The dielectric resonator has a dielectric constant of $\varepsilon_{\mathrm{r}}=15$ with thickness of $\mathrm{h}=3 \mathrm{~mm}$. One switch is located on one part of U-shaped feed line. The optimal dimension of the proposed antenna is represented in Table I.

TABLE I

\begin{tabular}{|c|c|c|c|}
\hline \multicolumn{4}{|c|}{ ANTENNA DIMENSIONS } \\
\hline Parameters & $\begin{array}{c}\text { Dimensions } \\
(\mathrm{mm})\end{array}$ & Parameters & $\begin{array}{c}\text { Dimensions } \\
(\mathrm{mm})\end{array}$ \\
\hline $\mathrm{W}_{0}$ & 40.0 & $\mathrm{~L}_{0}$ & 45.0 \\
\hline $\mathrm{W}_{1}$ & 4.2 & $\mathrm{~L}_{1}$ & 3.0 \\
\hline $\mathrm{W}_{2}$ & 2.0 & $\mathrm{~L}_{2}$ & 9.0 \\
\hline $\mathrm{W}_{3}$ & 18.0 & $\mathrm{~L}_{3}$ & 1.5 \\
\hline $\mathrm{W}_{4}$ & 1.0 & $\mathrm{~L}_{4}$ & 6.5 \\
\hline $\mathrm{W}_{5}$ & 20.0 & $\mathrm{~L}_{5}$ & 3.0 \\
\hline $\mathrm{W}_{6}$ & 3.0 & $\mathrm{~L}_{6}$ & 7.0 \\
\hline $\mathrm{W}_{7}$ & 34.0 & $\mathrm{~L}_{7}$ & 31.0 \\
\hline $\mathrm{h}$ & 3.0 & $\mathrm{~L}_{8}$ & 3.0 \\
\hline
\end{tabular}

\section{N UMERICAL INVESTIGATION}

The parametric study on the frequency bandwidth (reflection coefficient $<-10 \mathrm{~dB}$ ), gain and radiation pattern of the DR antenna is done by Microwave Studio software (CST), based on finite integration technique. One switch is used for frequency altering operations that is located on the feed line of the DR antenna. Therefore, two switching states, ON and OFF are design to obtain two wideband modes. For the implementation, the switch is a copper tab simulating the ideal switch. When this copper tab is connected (is closed), it demonstrates that the switch is ON state and when the tab is not connected, it indicates the OFF states. A rectangular DR is one of the important parameters to attain a wide bandwidth. As illustrated in Fig. 2, in the first wideband state, although the antenna structure without DR excited at two resonant frequencies - a center frequency of $4.15 \mathrm{GHz}$ and another of $7.4 \mathrm{GHz}$, the wide bandwidth is achieved by using the DR with permittivity of 15 . Moreover, the figure shows that by using DR, the wider impedance bandwidth is achieved on the second wideband state.

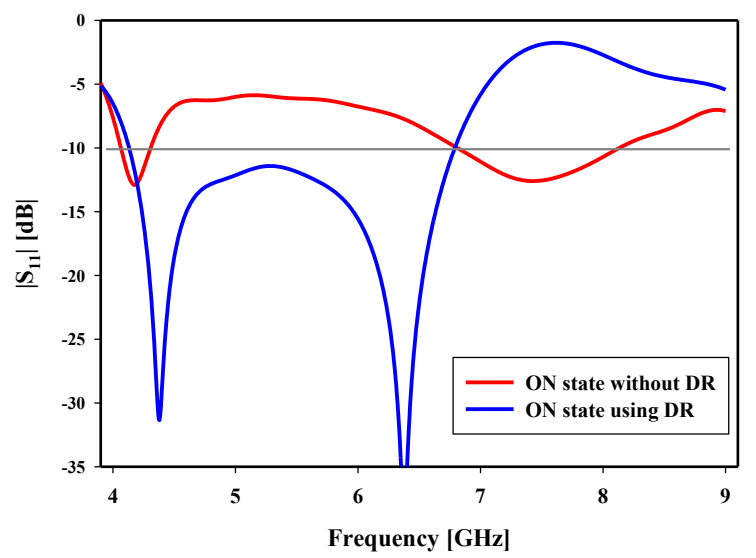

(a)

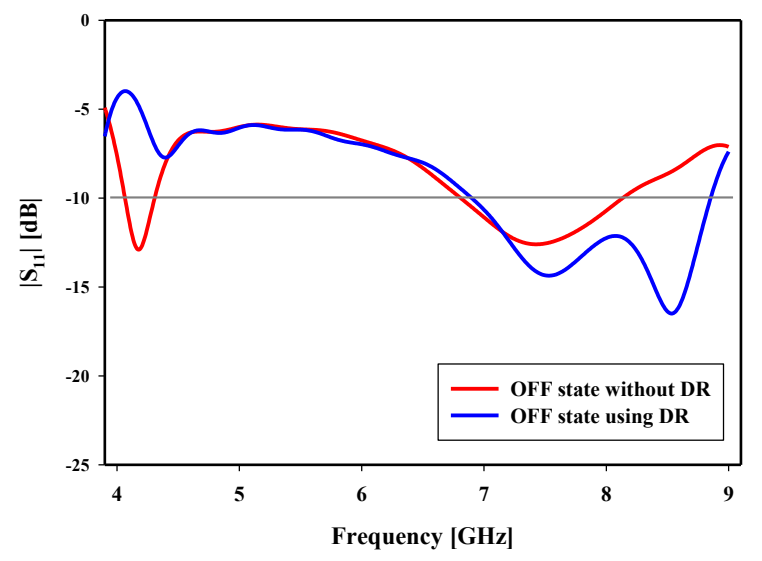

(b)

Fig. 2. Simulated $\left|\mathrm{S}_{11}\right|$ results with/ without using DR, a) ON state, b) OFF state. 
Furthermore, the ring-shaped ground plane configuration on the backside of the substrate increase the bandwidth, especially at the lower frequency. Fig. 3 shows the simulated reflection coefficient $\left(\left|S_{11}\right|\right)$ results for two wideband frequencies that are obtained with ideal switch. When the strip is connected (is closed), the switch is in the ON state; whereas it is in OFF state if the strip is not connected. As it clearly shown that in Fig. 3, the first wideband state is achieved when the switch is ON. This wideband frequency is started from $4.12 \mathrm{GHz}$ to $6.80 \mathrm{GHz}$ with the impedance bandwidth of $49 \%$. This state covers several applications such as WLAN and WiMAX. Another wideband is accomplished, when the antenna is in OFF state that covers frequency bands between $6.90 \mathrm{GHz}$ and $8.85 \mathrm{GHz}$. The achieved bandwidth in this mode is $25 \%$, which is used for some other applications such as $\mathrm{x}$-band satellite communications.

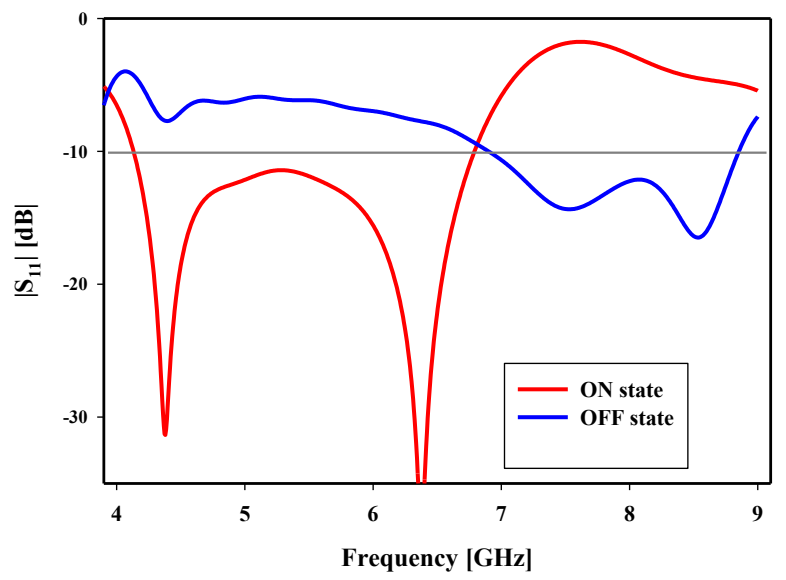

Fig. 3. Simulated $\left|\mathrm{S}_{11}\right|$ results in ON and OFF states.

The simulated gain and radiation efficiency versus frequency of the proposed antenna are illustrated in Fig. 4. It can be seen that the antenna achieves higher than $93 \%$ efficiency within the desired frequency in both wideband states and the gain is nearly constant with high value between 4.5 and $6.25 \mathrm{dBi}$. Fig. 5 illustrate the simulated radiation pattern of the proposed DR antenna in two wideband states at four resonant frequency of $4.4 \mathrm{GHz}$ and $6.4 \mathrm{GHz}$ in $\mathrm{ON}$ state, and $7.5 \mathrm{GHZ}$ and $8.5 \mathrm{GHz}$ in OFF state for $\mathrm{H}(\mathrm{xz})$ - and $\mathrm{E}(\mathrm{yz})$ - planes of the antenna. With the reference to Fig. 5, the H-plane is almost omnidirectional. However in both $\mathrm{H}$-, and E-plane in OFF state, the radiation pattern is much deformed and shifted due to the increasing frequency and asymmetric structure in this state and unbalanced current distribution of the proposed antenna. It is noticeable that, the proposed tunable DR antenna produces linear polarization over bandwidth modes.

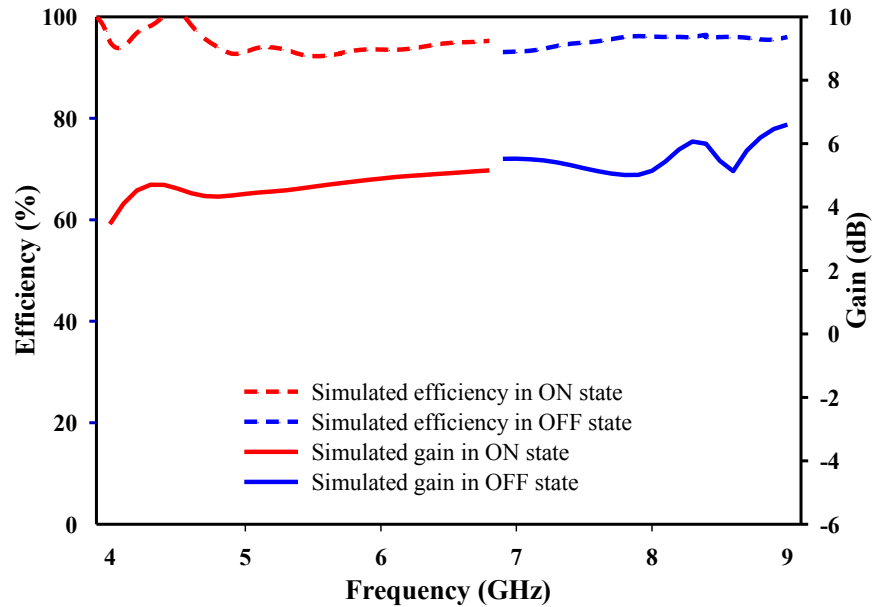

Fig. 4. Simulated radiation efficiency and gain of proposed antenna.

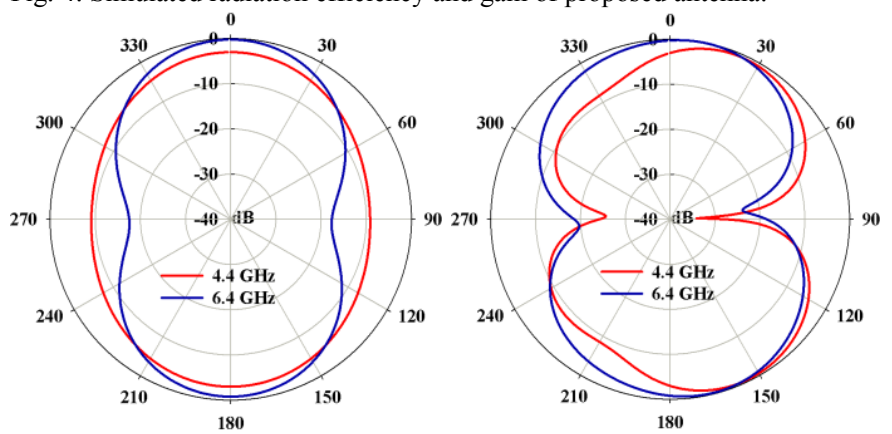

(a)

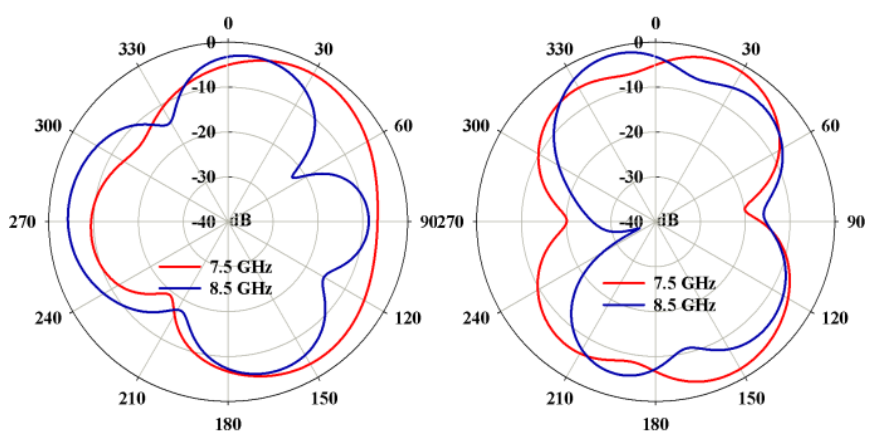

(b)

Fig. 5. The simulated radiation patterns of reconfigurable DRA. H(xz)- plane (left) and E(yz)-plane (right) (a) ON state GHz; and (b) OFF state.

\section{CONCLUSION}

A frequency reconfigurable dielectric resonator antenna presented to support two wideband operations. In this study, a reconfigurable DR, mounted on a microstrip U-shaped feed line, with the total low volume of $40 \times 45 \times 4.57 \mathrm{~mm}^{3}$ was discussed. One switch was used on the feed line path to create two wideband mode, by switching ON and OFF state. 
The antenna provides the frequency switching between 4.12 $\mathrm{GHz}$ and $8.85 \mathrm{GHz}$. The results indicate that the proposed antenna will be able to support numerous types of wireless systems such as WLAN, WiMAX and $\mathrm{x}$-band satellite communications.

\section{ACKNOWLEDGMENT}

The authors would like to thank the Ministry of Education and Universiti Teknologi Malaysia for sponsoring this work under FRGS Grant (Vot 4F283) and RUG (11H59\&00M69). Also special thanks to UTM for Post-Doctoral Research Grant (Vot 02E37) that has supported the author to do this research.

\section{REFERENCES}

[1] Yang Gao, Zhenghe Feng, and Li Zhang, "Experimental Investigation of New Radiating Mode in Rectangular Hybrid Dielectric Resonator Antenna" IEEE Antennas Wireless Propagation Letters, vol. 10, pp. 91-94, 2011.

[2] M. Abedian, S. K. A. Rahim, Sh. Danesh and M. Khalily, "Ultrawideband Dielectric Resonator Antenna with WLAN band rejection at $5.8 \mathrm{GHz}$," IEEE Antennas Wireless Propagation Letters, vol. 12, pp. 1523-1526, 2013.

[3] M. Abedian, S. K. A. Rahim, Sh. Danesh, S. Hakimi, L. Y. Cheong, and M. H. Jamaluddin, "Novel Design of compact UWB Dielectric Resonator Antenna with Dual Band rejection Characteristics for WiMAX/WLAN Bands," IEEE Antennas Wireless Propagation Letters, vol. 14, pp. 245-248, 2015.

[4] C. X. Hao, B. Li, K.W. Leung, and X. Q. Sheng, "Frequency-Tunable Differentially Fed Rectangular Dielectric Resonator antennas," IEEE Antennas Wireless Propagation Letters, vol. 10, pp. 884-887, 2011.

[5] Sh. danesh, S. K. A. Rahim, M. Abedian, M. Khalily, and M. R. Hamid "Frequency Reconfigurable Rectangular Dielectric Resonator Antenna" IEEE Antennas Wireless Propagation Letters, vol. 12, pp. 1331- 1334, 2013.

[6] Hattan F. Abutarboush, R. Nilavalan, S. W. Cheung, Karim M. Nasr, Thomas Peter, Djuradj Budimir, and Hamed Al-Raweshidy, "A Reconfigurable Wideband and Multiband Antenna Using Dual-Patch Element for Compact Wireless Devices," IEEE Transaction on Antennas Propagations, vol.60, pp. 36-43, Jan. 2012.

[7] Jusoh, M., Jamlos, M. F. and Kamarudin, M.R. “A Compact Dual Bevel Planar Monopole Antenna with Lumped Element for Ultra High Frequency/Very High Frequency Application", Microwave and Optical Technology Letters (MOTL), Volume: 54, Issue: 2, Page (s): 156 - 160, 2012.

[8] Hoi Kuen Ng and Kwok Wa Leung, "Frequency Tuning of the Linearly and Circularly Polarized Dielectric Resonator Antennas Using Multiple Parasitic Strips," IEEE Transaction on Antennas Propagations, vol.54, pp. 225-230, Jan. 2004.
[9] K. K. So and K. W. Leung, "Bandwidth Enhancement and Frequency Tuning of the Dielectric Resonator Antenna Using a Parasitic Slot in the Ground Plane," IEEE Transaction on Antennas Propagations, vol.53, pp. 4169-4172, December. 2005.

[10] T. Apperley, and M. Okoniewski, "An Air-Gap-Based Frequency Switching Method for the Dielectric Resonator Antenna” IEEE Antennas and Wireless Propagation Letters, 2014. 13: 455-458.

[11] Danesh S., S. K. A. Rahim, M. Abedian, and M. R. Hamid "A compact Frequency Reconfigurable Rectangular Dielectric Resonator Antenna for LTE/WWAN and WLAN applications" IEEE Antennas Wireless Propagation Letters, vol. 14, pp. 486- 489, 2015.

[12] Sh. danesh, S. K. A. Rahim, and M. Abedian, "Frequency Reconfigurable Rectangular Dielectric Resonator Antenna for WiMAX/WLAN Applications" Microwave and Optical Technology Letters, vol. 57, No. 3, pp. 579-582, 2015.

[13] G. O'Keefe and S. P. Kingsley, "Tunability of liquid dielectric resonator antennas," IEEE Antennas Wireless Propagation Letters, vol. 6, pp. 533-536, 2007.

[14] A. Petosa and S. Thirakoune, "Frequency tunable rectangular dielectric resonator antenna," Antennas and Propagation Society International Symposium, 2009. APSURSI '09. IEEE, pp.1, 4, June 2009. 